\title{
Methods about Imagination Education in Architecture
}

\author{
Wei Zhang ${ }^{1, a}$, Jianqiu $\mathrm{Yu}^{2, \mathrm{~b}}$ \\ ${ }^{1,2}$ School of Resource and Civil Engineering, Wuhan Institute of Technology, Wuhan, Hubei, China, \\ 430073, \\ ajannet2005@163.com, byujq200366@126.com
}

Keywords: architecture, imagination, creative thinking.

\begin{abstract}
This paper analyzes the importance to strengthen the imagination education in architecture. It puts forward a series of methods to stimulate students' imagination, such as guiding students to read a lot, setting a serious of imagination training work, commenting the students' imaginative design with respect, and introducing practice in theory courses, developing students' comprehensive and scientific view of architecture innovation.
\end{abstract}

\section{Introduction}

When we open the vast history of human civilization, we can find the development of major invention and discovery in science and technology, always began from imagination. No matter the use of fire and tool, the exploration of the universe or the discovery of molecules and atoms, are all reflecting creative imagination of human being.

Innovation is the soul and inexhaustible power for a nation's progress.

\section{Architecture especially needs to strengthen the imagination education.}

Architecture is a combination of art and technology, it is not only a natural science, but also closely related to social science and art, it has particularly demands for creativity and imagination.

Classical architecture, such as the Eiffel Tower, the Sydney Opera House, Centre National d'art et de Culture Georges Pompidou, Chinese National Stadium, they all reflect the rich imagination about architectural appearance, function and technology. It is creative thinking that can promote architectural renewal constantly.

However, the present status of architecture design in China is that there are a large number of copycats and fashion followers, many architects' work are just using scissors and paste to make a patchwork. Big roofs, European style, postmodernism, deconstruction..... they take turns to be copied. Buildings have exaggerated fashion appearance, but regionalism, originality are lost. It's hard to feel the thinking and soul of the architecture. These can be attributed to the barren imagination and creativity of the designers, it can also reflect the shortage of architecture education in our country.

Chinese architecture requires real creativity, where does its survival system come from? It must be from education.

\section{How to develop imagination education in architecture?}

For architecture students, imagination is so important, how can we develop?

\section{Extensive reading and observation should be the basis of imagination.}

Human innovation is based on inheritance, and imagination is inseparable from the memory of the traditional image. Processing, transformation and comprehensive of memories can create a new image.

In order to cultivate the students' imagination, the first thing is to guide them in deep and extensive reading, observation and thinking. 
Now in China architecture belongs to engineering, enrollment is usually done in science students, these science students often pay more attention to logical thinking than imagination. Teachers familiar with architect education can find students who have higher college entrance scores often do not have advantage compare to those who have lower scores. Architecture students' academic performances are facing large reshuffle after admission. Students who have professional advantages always read widely, well informed, instead of gaining higher scores in high school.

Architecture is a practice subject, through reading and observing, students can have more materials to link in the design. "Read thousands of books, walk thousands of miles", a Chinese rule from the ancient is particularly true in architecture study.

\section{Plenty of imagination training assignments should be set in architecture education.}

In a series of architecture lessons, we should not only teach students knowledge, but also inspire them to imagine. Imagination training assignments are direct. For example, as a fundamental course of architecture, the Initial of Architecture tends to stress the various skill training, such as line practice, measuring and drawing, rendering and composition training, etc. It seems that the lesson is just about skill training under the rules. Students can learn how to do correctly through training, but it is not enough to inspire students' interest on creative design thinking, we should add more imagination assignments. For example, we can set a small assignment such as "describe the future building in your mind". For beginners, describe their ideas unconstrained can inspire their imagination.

The architecture courses can be divided into two categories, design courses and theory courses. Teachers should use a variety of forms, mobilize the initiative of students, develop their imagination and dig their creative potential.

\section{Comments on students' design should fully respect the student's imagination.}

Architecture design courses are undoubtedly core courses throughout the whole process of this major, they directly decide the students' design ability.

Each design can be the student's original design. The teachers should keep in mind to affirm their achievements, encourage innovation when give comments on students' design, especially for those who have special ideas. Student's heart is fragile, simple critics like "unreasonable or cannot do" may kill their imagination, dampen their enthusiasm. This is not just about the art of language, but the protection of students' imagination and enthusiasm. In architecture design we should encourage and support the students to try and take risks.

For example, students like to do some concrete design, they often design buildings similar to a snail, footprint, tree, flower, plant and so on, it always causes talking and laughing. As a teacher, we cannot simply deny such designs, we should give full affirmation to its reasonable parts, such as its imagination and creativity, its uniqueness, and then guide the student to study abstract form treatment methods. For cultivating imagination, we should treat them as young flowers just bud, we should cherish, care, encourage them. We shouldn't put out the spark of imagination because of our careless and kill their young imagination.

\section{Comprehensive and scientific view of architecture innovation should be cultivated.}

We need to cultivate comprehensive and scientific view of architecture innovation. We should teach students to recognize that architecture is not only an art, but also a comprehensive engineering. Architecture design should be a combination of function, technology, and aesthetics under certain conditions, although exists primary and secondary, either should not be ignored. Architecture design should not be regarded as a pure art making, and put the form in the first place. It will damage the function and technology aspects, and break the integrity of architecture design.

Just as high-rise buildings occurred accompany with the emergence of elevator equipment. New materials such as steel, glass used in building help to generate the Eiffel Tower, the Crystal Palace. 
Tension structure, grid structure, suspended cable structure, reinforced concrete shell structure gave rise to various large roof and large space buildings.

Chinese National Stadium designed by Herzog (figure 1) was woven with steel truss structure, National Olympic Gymnasium designed by Kenzo Tange (figure 2) used the cable structure, these are new structure our predecessors have not tried, they are perfect combination of structure, material, technology, function and esthetics, and they are innovation architecture.

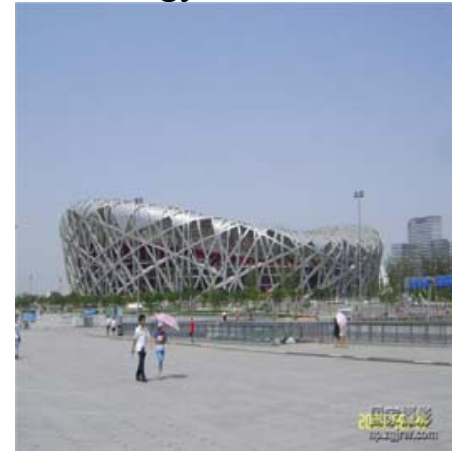

Fig.1 Chinese National Stadium designed by Herzog

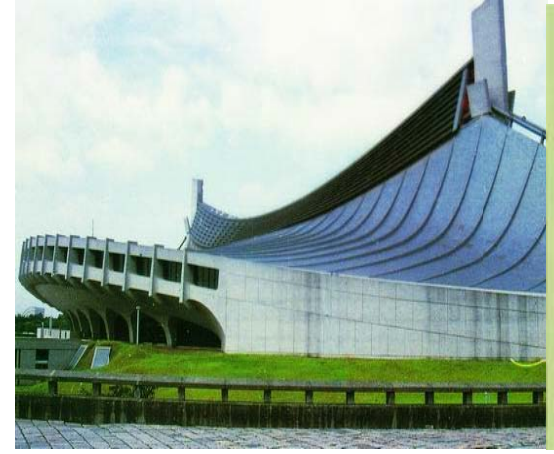

Fig.2 National Olympic Gymnasium designed by Kenzo Tange

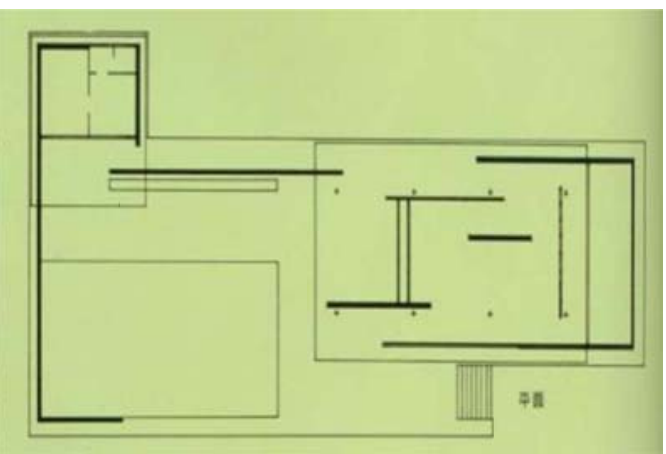

Fig.3 Barcelona Germany pavilion designed by Ludwig Mies Van der Rohe

Barcelona Germany pavilion designed by Ludwig Mies Van der Rohe (see figure 3) created flowing space, make people continuous, uninterrupted space experience. Function innovation of modern hospital, breaks away from the original heavy, dirty, depressing atmosphere, brings different people different care. For example: the children's hospital (see figure 4) nowadays always builds a lively, bright, friendly environment; maternity hospital nowadlays always builds a comfortable, warm home feeling.

Architecture innovation should not only in form, but also in function, space, structure, material, equipment, physical technology. They constitute a complete appearance of architecture innovation. We should pay attention to inject such design consciousness in teaching.

\section{Practice should be introduced to theory courses to stimulate students' imagination}

As the saying goes: Real knowledge comes from practice. A large number of theory courses such as architecture history, architecture physics, materials, equipment, structure and construct can not only be the classroom teaching. They all have scientific enlightenment function, they can also cultivate the creative thinking. We should inject the corresponding practice contents to help students exploring the principle and technology in practice.

Imagine: how can students who just passively accept the thin shell structure theory creatively use these thin shell structure to create a new architecture appearance?

So, when we are in the Chinese architecture history class, we can organize students to traditional local-style dwelling houses, temples to see and consider what is mortise and tenon joint structure (see figure 5), guide the students to experience by themselves. In the future, they can consciously embody traditional culture spirit in their design.

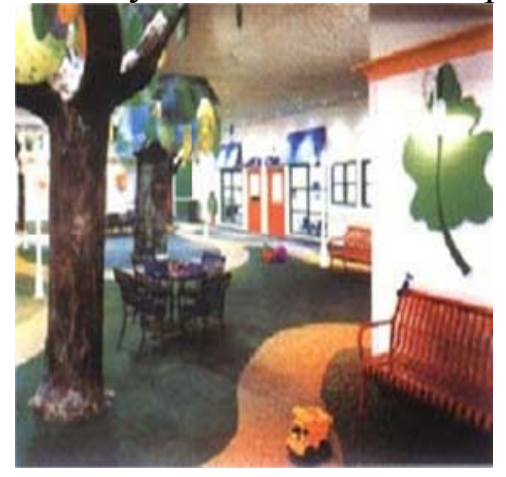

Fig. 4 children's hospital different from the past

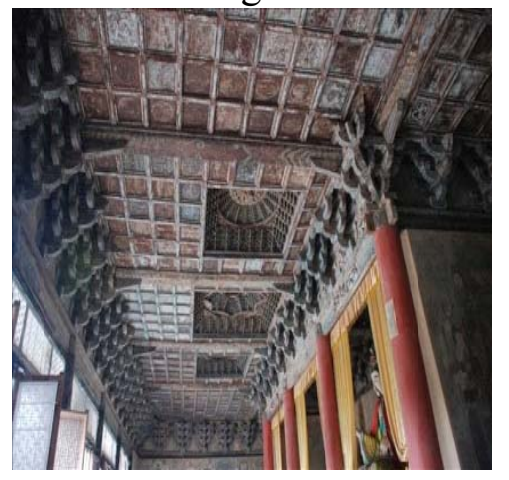

Fig 5 mortise and tenon joint structure

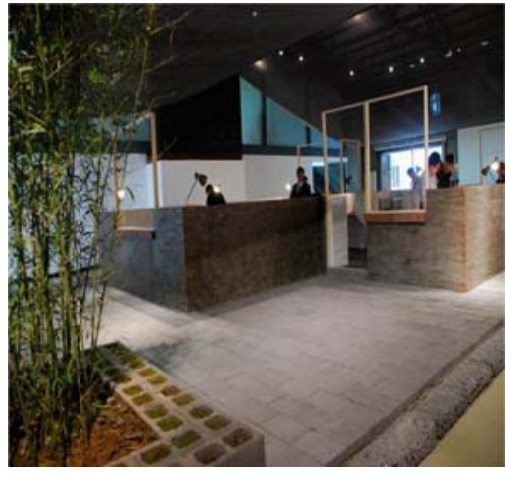

Fig 6 Chinese architect Liu Jiakun exhibited his "renewable brick" project 
In architecture material class, we can guide students to use various materials to do some nodes, fragments by themselves, thus they can be familiar with the material characteristics. In future, they can have the ability to creatively use material (see figure 6).

Field practice teaching must play an important role in theory lessons, lay a good foundation for cultivating the students' creativity.

Regardless of which courses, we should consistently held in mind to encourage and cultivate students' imagination, and we can find the right breakthrough point in each course, thus systematically train the students' imagination and creative thinking.

\section{Summary}

As Einstein said, "imagination is more important than knowledge, because knowledge is limited, but imagination summarizes everything in the world, driving the progress, and is the source of knowledge". As a university teacher, we should make full use of a variety of means to give contemporary college students imagination education, this will be their lifelong creativity source. Architecture is a major specially needing creativity, there is no architecture development without imagination and creative thinking. An architect without creativity can only be a follower and a copycat, always at the edge of time. It can be said that the rise of Chinese architecture tomorrow is based on whether we can train creativity today. Our architecture education, should not only pay attention to surface's ability to adapt to society, but also to deep ability of creativity.

\section{References}

[1]Shao Yu, Zou Guangti, foreign Architectural design innovation education and its enlightenment. [J] Architectural Journal, 10(2008), 66-67.

[2] Xiang Shang, Discussion about architecture education innovation in China from the British education and certification system of architects (1), Architecture Times, 2/9/2013, 008 edition.

[3] Xiang Shang, Discussion about architecture education innovation in China from the British education and certification system of architects (2), Architecture Times, 16/9/2013, 008 edition.

[4] Ding Yuhong, A Probe into Innovation-Centred Contemporary Architectural Education-— The Revelation from AA School of Architecture, London, UK, [J]Chinese and Overseas Architecture, 07( 2010): 58-61.

[5] Creative spirit is the primary responsibility of Architectural Education-—The Interview to Dean of Bartlett School of Architecture University College London Marcus Cruise, [J]Architecture \& Culture, 05(2011): 008-013. 